\title{
APLICACIONES GRÁFICAS INFORMATIZADAS EN ARQUEOLOGÍA
} COMPUTERISED GRAPHIC APPLICATIONS IN ARCHAEOLOGY

por

\author{
LEONARDO GARCIA SANJUAN
}

\begin{abstract}
RESUMEN En este trabajo se discuten varias aplicaciones gráficas informatizadas y su utilidad en investigación arqueológica, gestión de patrimonio y museología haciendo particular hincapié en la situación andaluza actual.
\end{abstract}

\begin{abstract}
This paper outilines briefly the range of computer graphics applications in archaeological research, manegement and education, stressing the current situation in Andalusian Archaeology.
\end{abstract}

\section{INTRODUCCION}

Desde que en los años sesenta la Arquelogía Procesual o (entonces) "Nueva" estableciera las bases sobre las cuales nuestra disciplina debía ser considerada una ciencia moderna, la Arqueología ha conocido cambios relevantes, muchas veces dramáticos, en muchos países. Despues del "año de las barricadas" (Shennan, 1989), en el que se publicaron libros de gran trascendencia posterior (BinfordBinford, 1968. Clarke, 1968), la Arqueología perdió subsecuentemente su tradicional "inocencia" (Clarke, 1973), comenzando una difícil y larga lucha por transformarse en una ciencia social. Así, en las dos últimas décadas, discusiones ya anteriormente relevantes en otras actividades de investigación han venido a tener lugar en Arqueología en varios niveles diferentes.

En un nivel puramente epistemológico, la discusión se ha centrado en problemas tales como la posibilidad de definir leyes o regularidades en el comportamiento humano pasado a través de la Arqueología, la adecuación del método hipotético-deductivo en el razonamiento arqueológico en contraposición al tradicionalmente empleado inductivismo, la posibilidad de definir una teoría general de sistemas arqueológicos, etc.

Acerca de la conceptualización arqueológica de las culturas y sociedades humanas, la nueva arqueología norteamericana propuso por primera vez un entendimiento holístico y comprensivo del registro 
arqueológico, asumiendo básicamente una visión funcionalista tomada de la Ecología Cultural de Leslie White (Binford, 1962). En general, en Europa, el debate ,que ha tendido a concentrarse en países septentrionales (Shennan, 1987), se ha dirigido a aproximaciones tomadas del materialismo, el estructuralismo, o simplemente el ideacionismo tradicional de la historiografía europea ahora renovado como post-procesualismo (Hodder, 1986). Los muy diferentes orígenes y tradiciones historiográficas explican probablemente al menos parte de la evolución diferencial del debate teórico en el Nuevo y el Viejo Mundo: Arqueología como Historia del Arte en Europa y como Antropología en América (Alcina, 1975).

Sea como sea, como una consecuencia directa de la demanda procesualista de un debate antropológico más que estrechamente arqueológico, se ha producido un interés creciente en el debate sobre la naturaleza de la cultura humana a través de la Arqueología. Esto ha hecho a la Arqueología establecer su propio lugar en el entramado de Ciencias Sociales, algo que ya puede ser considerado en sí mismo un notable progreso respecto al paradigma en que aquélla se encontraba anteriormente.

Pero quizás haya sido en la esfera metodológica donde los cambios más impactantes se han operado. Como otra consecuencia inmediata del entendimiento dialéctico de la relación cultura-medio por parte del procesualismo, un vasto número de técnicas físicas, químicas y biológicas comenzaron a ser integradas en el diseño de la investigación arqueológica generando la información apropiada sobre paleoambiente y paleoeconomía. La definición del "interfaz" entre la Arqueología y esas otras disciplinas no está siendo fácil (Aspinall, 1986.Vila, 1989), pero los resultados están siendo elocuentes en forma de una comprensión mucho más global e integrada y no estrechamente positivista de las culturas arqueológicas.

Más relevante para el propósito de este artículo es la revolución que ha ocurrido en la forma que los arqueólogos han empezado a recoger, analizar, sintetizar e interpretar sus datos, una revolución definitivamente incomprensible si no consideramos el papel de los ordenadores en Arqueología durante los últimos veinte años. Dos razones principales parecen emerger como causas de la inclusión inicial de los ordenadores en Arqueología :

- Desde un punto de vista teórico fue una vez más una propuesta típicamente procesualista la que desencadenó el proceso. Siendo la cultura considerada como "multivariada" (Binford, 1962), la demanda de una análisis estadístico multivariado de los datos encaminado a definir dentro de un marco lógico de razonamiento (y no un marco subjetivo-individual) las relaciones entre variables predefinidas y justificadas teóricamente, trajo a los ordenadores dentro de la Arqueología. Como S. Shennan (1988) ha señalado :

"...statistical analysis was the purpose for which computers were first introduced into archaeology."

Por otra parte, razones de índole más práctica contribuyeron a la consideración de los ordenadores como una adquisición positiva de la Arqueología, conforme a finales de los sesenta, la gestión del patrimonio arqueológico por parte de la administración pública en varios paises se tradujo en una fuente imparable de producción de datos arqueológicos que necesitaban sistemas eficaces y rápidos de almacenamiento y gestión.

La extensión y relevancia de esta revolución ha venido quedando jalonada en la literatura por la creación de revistas y conferencias regulares sobre informática arqueológica o sistemas arqueológicos de información. Advances in Computing Archaeology (EEUU), Lettre d'ínformation: Archeologie et ordinateurs (Francia), KARK (Dinamarca), Archaeological Computing Newsletter (Reino Unido) y Archeologia e Calcolatori (Italia) figuran entre los casos más conocidos. Las actas de las CAA británicas se han convertido desde 1987 en una publicación anual que refleja las últimas tendencias. Publicaciones no especializadas en el tema han reflejado asimismo el impacto de los métodos cuantitativos y 
los ordenadores durante los últimos años; este es el caso de American Antiquity, Archaeometry, Journal of Archaeological Science, World Archaeology o Science and Archaeology, por sólo mencionar unos casos.

Una ojeada a la literatura publicada en Europa (Ryan, 1988. Arroyo-Lantada, 1990b) sobre el tema sugiere que, comparativamente, en nuestro país este proceso ha comenzado más tarde y se está desarrollando con cierta lentitud. Las condiciones que detonaron las aplicaciones informaticas arqueológicas en el Reino Unido o los EEUU, ya mencionadas, están actualmente cada vez más presentes en la Arqueología española:

- Por un lado existe un creciente interés en desarrollar un nuevo tipo de razonamiento arqueológico vinculado al análisis estadístico (Barceló, 1989. Nocete, 1989), que conduce inexorablemente a la automatización del manejo de los datos (Figura 1).

- Por otro, cada comunidad autónoma ha establecido su propio sistema de gestión de los recursos culturales en general y del patrimonio arqueológico en particular, facilitando medios humanos y materiales para detener su deterioro. Durante los últimos cuatro o cinco años muchas unidades arqueológicas provinciales y regionales han estado generando crecientes cantidades de información que han provocado serios problemas de almacenamiento, análisis y publicación. Ello ya ha motivo aproximaciones a las tecnologías de la información (TEDA, 1990), aunque el camino a recorrer parece aún bastante largo (Arroyo-Lantada, 1990a). La integración de esa información en el planeamiento urbanístico y la gestión del patrimonio natural a través de los sistemas geográficos de información para minimizar la destrucción de yacimientos es todo un reto que se plantea en la actualidad a la Arqueología de gestión española.

De alguna forma los ochenta han sido un periodo de concienciación para la Arqueología española en muchos sentidos: en el campo específico de las aplicaciones informáticas ${ }^{1}$ estamos en el punto de arranque de desarrollos interesantes, como sugieren las conferencias que han tenido lugar en Madrid recientemente (Fernández, 1991). Probablemente no es por casualidad que el último manual de teoría y método arqueologicos publicado en España (Fernández, 1989) dedique dos capitulos enteros a esbozar el espectro de aplicaciones cuantitativas e informáticas en Arqueología.

En este contexto, el propósito de este artículo es comentar una serie de aplicaciones arqueológicas de programas diseñados con propósitos gráficos. Puesto que el campo a cubrir es enormemente vasto y diverso, incluyendo múltiples aproximaciones y problemas, existe un riesgo obvio de caer en la superficialidad. Sin embargo, creo que merece la pena asumir el mismo si con ello se estimulan nuevas aproximaciones a las tenologías de la información en la Arqueología española en general y en la andaluza, a la cual se hace particular referencia, en concreto.

En un primer apartado se tratan aplicaciones gráficas con propósitos analíticos, es decir, donde el gráfico computerizado es un instrumento esencial para una mejor interpretación de los datos analizados. En un segundo apartado son tratadas las posibilidades de los gráficos computerizados en lo que podríamos denominar el "interfaz" social de la Arqueología, aprovechando un término común en Informática, a través del modelado sólido y los hipertextos. Finalmente se esboza el papel potencial de los ordenadores en la formación universitaria de los arqueólogos.

1. Los primeros trabajos arqueológicos asistidos por ordenador aparecen en España a mediados de esta década (Sánchez, 1985), (Sánchez, 1986), (Montero-Montero, 1984), (Olaría-Gusi, 1984), (Choclan et alli, 1984), (Lucas et alii, 1986), (DPUG, 1986), aunque todavía en 1989, una encuesta realizada sobre el uso de ordenadores en instituciones de investigación arqueológica (Fernández-Fernández, 1989) mostraba una escasa implantación del mismo en la Comunidad autónoma andaluza. 

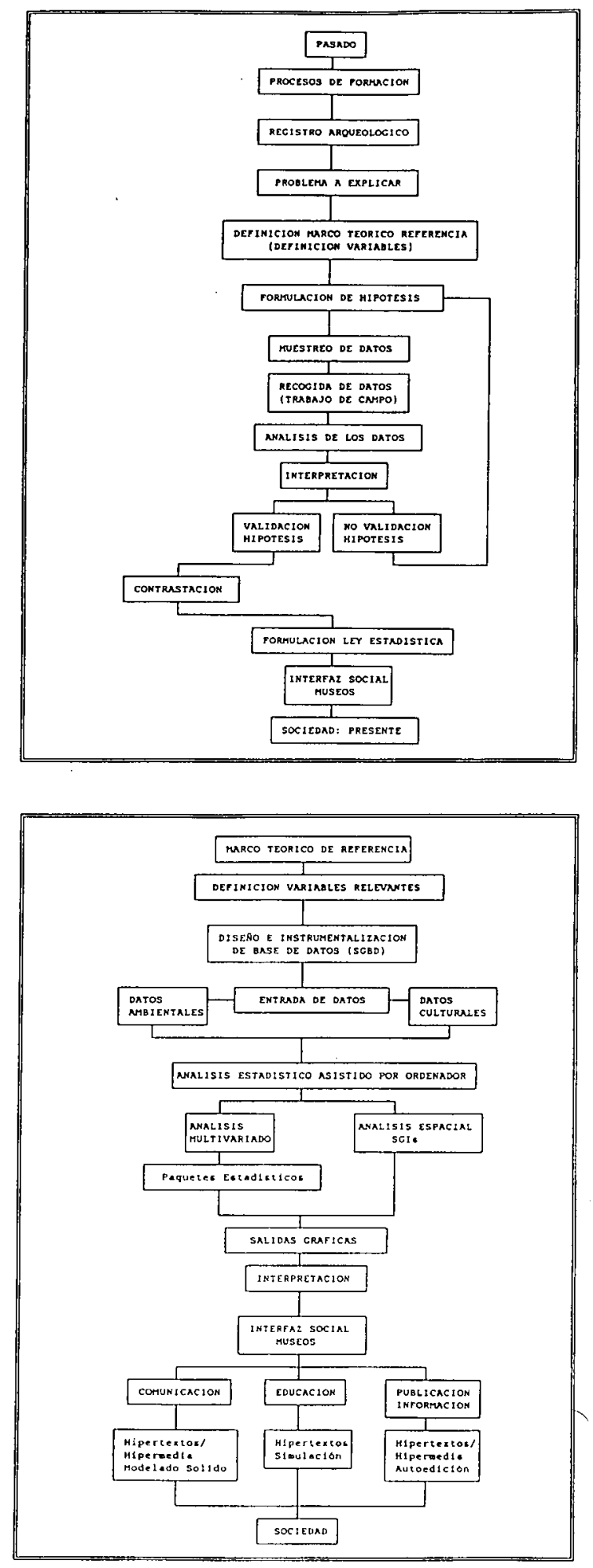

Fig. 1. Informática en Arqueología 


\section{GRAFICOS ESTADISTICOS}

No es necesario insistir demasiado en la importancia que los sumarios gráficos tienen en la presentación y análisis de los datos arqueológicos. Es ésta la parte decididamente analítica de la informatización de los gráficos arqueológicos, puesto que supone la creación de imágenes que aportan una visión nueva de los datos empíricos susceptible de interpretación y contrastación. En esta sección no voy a discutir el empleo de gráficos estadísticos comunes, sean descriptivos, sean producto de un análisis multivariado de los datos, como base de la inferencia arqueológica. Existen numerosos paquetes estadísticos de propósito general cuyo uso en Arqueología es habitual desde hace años (Shennan, 1988. Ryan-Richards, 1985), y varias universidades extranjeras han producido y comercializado programas de análisis de datos de orientación específicamente arqueológica (Hodson-Tyers, 1988. Wright, 1989). Mas bién me interesa presentar dos ejemplos de aplicaciones gráficas basadas en el análisis de datos arqueológicos espaciales a escala micro/semi-micro y a escala macro.

\section{II.1. Gráficos a escala micro o semi-micro}

El estudio de la distribución espacial de artefactos ha sido considerado determinante en la investigación de la funcionalidad de las distintas áreas de un yacimiento (Hodder-Orton, 1976). Consiguientemente, la generación de gráficos que muestren la densidad de cada item en las unidades de excavación, o en las estructuras arquitectónicas, adquiere una importancia relevante. Como ejemplo de la asistencia que un software especializado puede prestar al arqueólogo en esta fase de su investigación bien puede valer el sistema UNIRAS (UNiversal RAster System), que proporciona aplicaciones gráficas de alto nivel. Dejando de lado su entorno programador, usuarios no programadores pueden desarrollar múltiples aplicaciones con los cuatro módulos menu-driven que el sistema ofrece: UNIGRAPH (gráficos de estadística descriptiva), UNIMAP (sistema cartográfico) UNIEDIT (sistema de diseño y dibujo) y UVF (edición de cualquier producto generado en los módulos anteriores).

Centrándonos en UNIMAP (UNIMAP, 1989) por su propósito explícitamente espacial, el sistema reconoce dos tipos de datos: regulares e irregulares. Los datos irregulares son aquellos espacialmente referenciados de forma aleatoria, y su entrada se realiza por medio de diferentes columnas de números: las dos primeras representan las coordenadas $\mathrm{X}$-Y, siendo las siguientes $\mathrm{Z}_{\mathrm{n}}$ columnas los valores observados para esa/s variable/s en estudio. Los conjuntos de datos regulares son entrados como series de valores $\mathrm{Z}$, puesto que las coordenadas $\mathrm{X}-\mathrm{Y}$ pertenecen a una cuadrícula ya conocida. Como ya se habrá observado, el procedimiento de entrada se adecúa perfectamente al sistema habitual de registro de campo por triangulación popularizado por los paleolitistas como método "Laplace-Meroc".

Una vez que, por ejemplo, se ha registrado la localización de una serie de piezas líticas de desecho de un taller, se puede reflejar espacialmente la variabilidad de variables tales como dimensiones, peso, naturaleza litológica, etc. (es decir los valores $\mathrm{Z}$ mencionados anteriormente), usando los datos en bruto $\mathrm{o}$ interpolándolos, de una forma bi o tridimensional, $\mathrm{y}$, con la ayuda de gráficos en color, proceder a una interpretación de la misma.

En las Figuras 2,3 y 4 se muestra una serie de gráficos realizados utilizando información inédita referida al grosor máximo de las paredes de los fragmentos de ánforas hallados en una cuadrícula situada en la periferia inmediata de un alfar romano. Se pretende investigar si estas piezas de desecho presentan un patrón en su distribución, y si ello puede ser reflejo de una diferencial funcionalidad con respecto a otras áreas periféricas. Con este fin se han elaborado cinco gráficos usando UNIMAP.

El primer gráfico (Figura 2a) ofrece bidimensionalmente la distribución de los items en la cuadrícula, mientras que cada tonalidad de color se incluye en grandes grupos separados por el umbral de dos 
Fig. 2. Gráficos Unimap

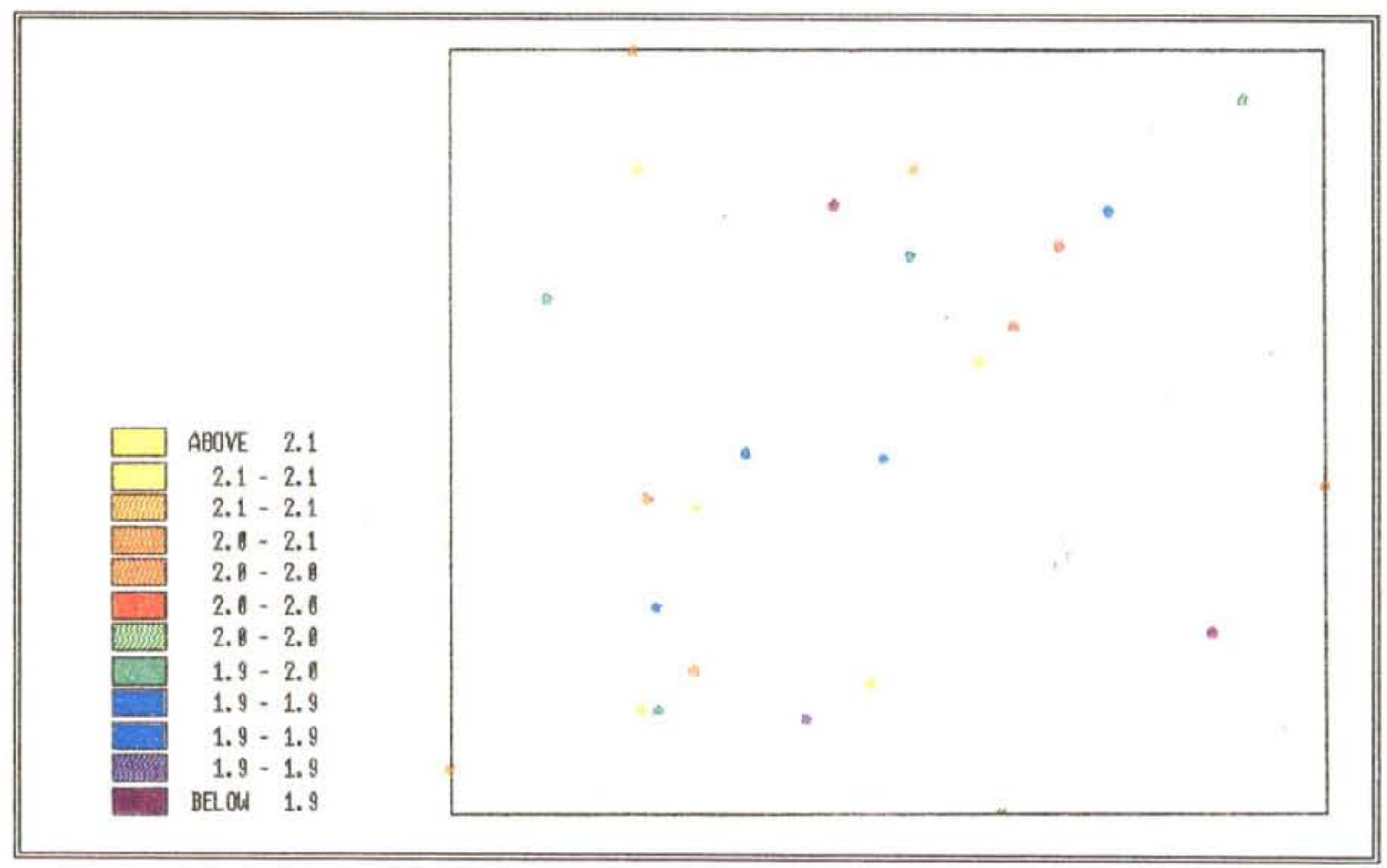

2a. Gráfico de puntos bidimensional

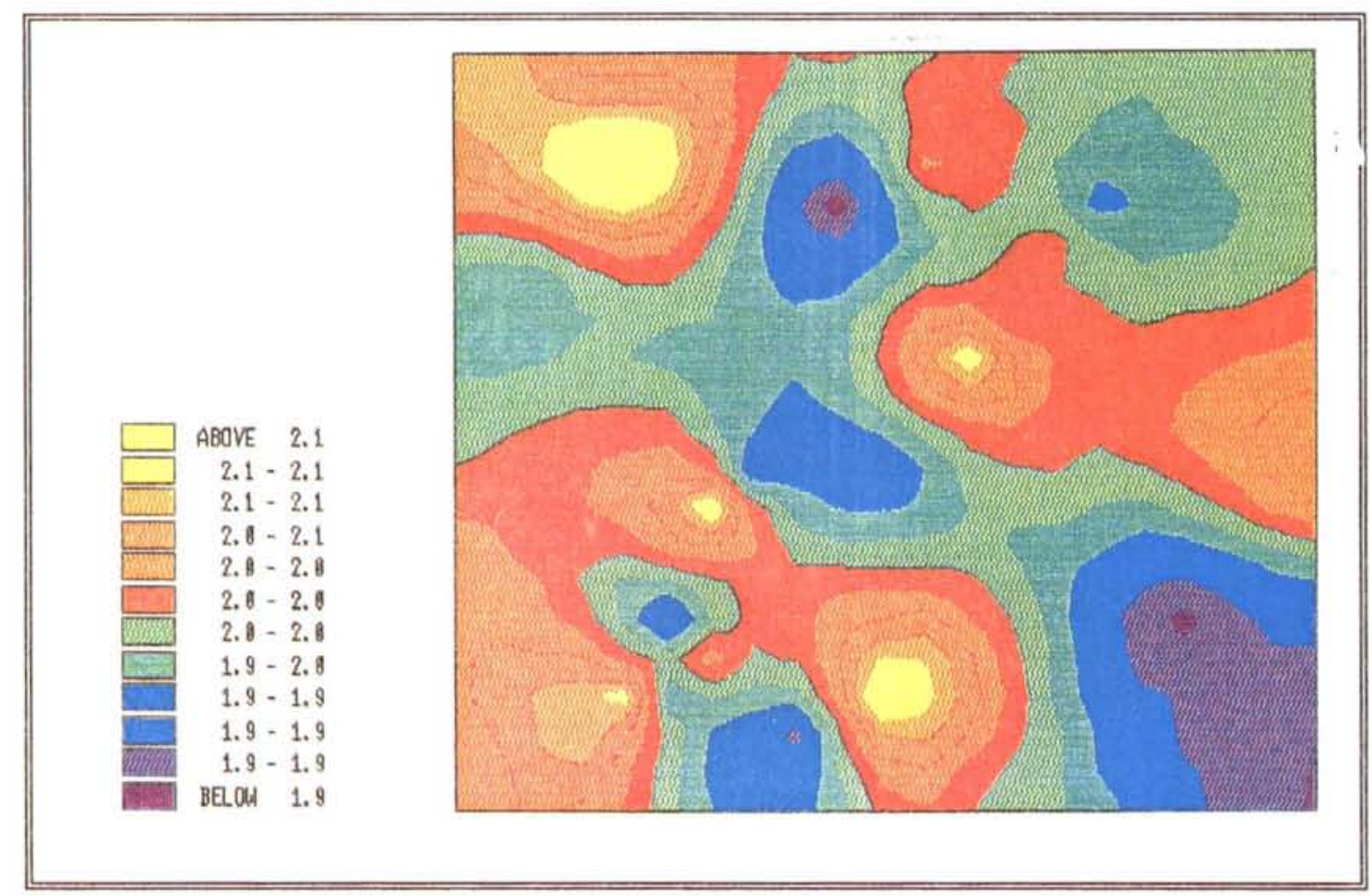

2b. Gráfico de contornos interpolados bidimensional 
Fig. 3. Gráficos Unimap

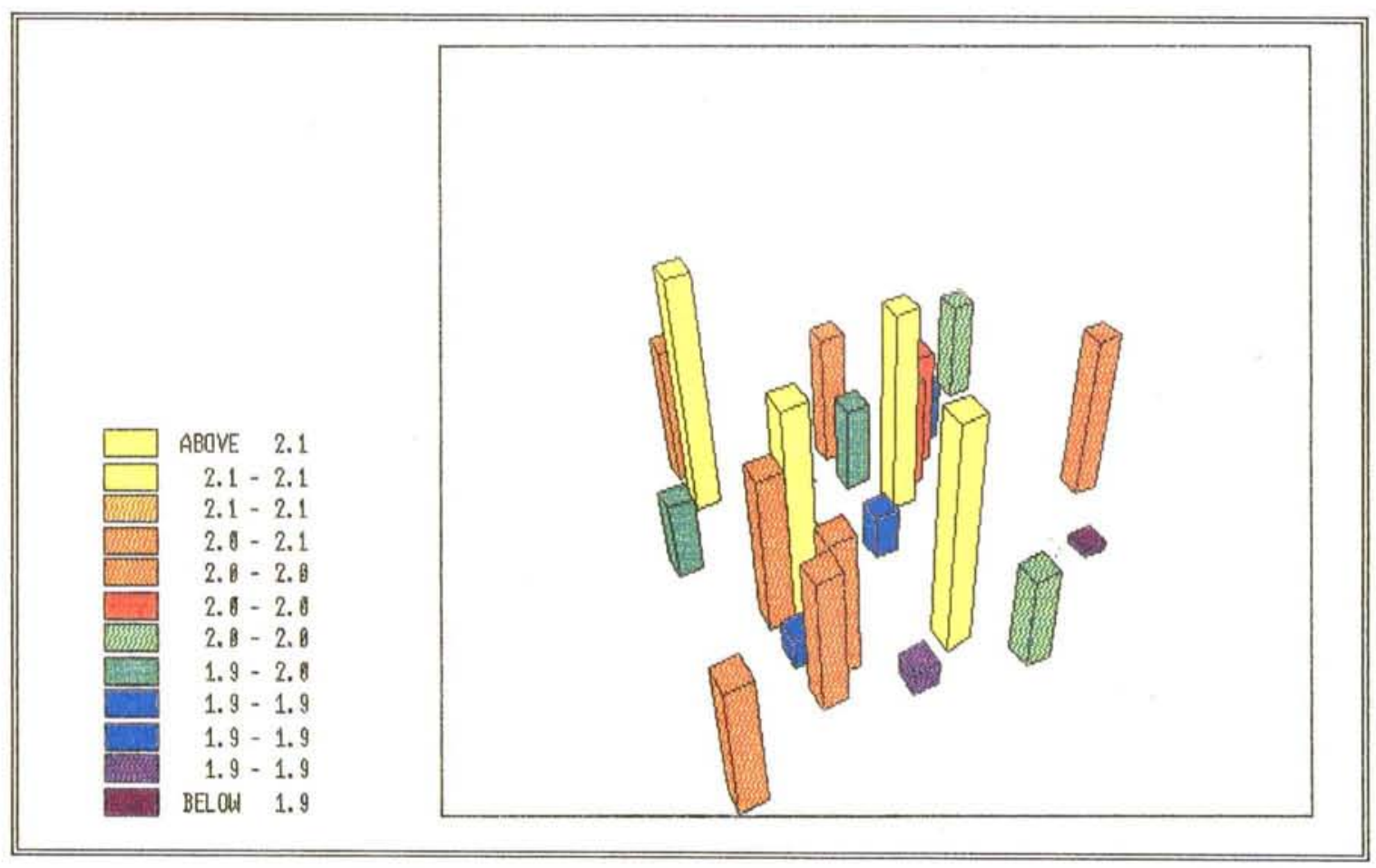

3a. Gráfico de puntos tridimensional

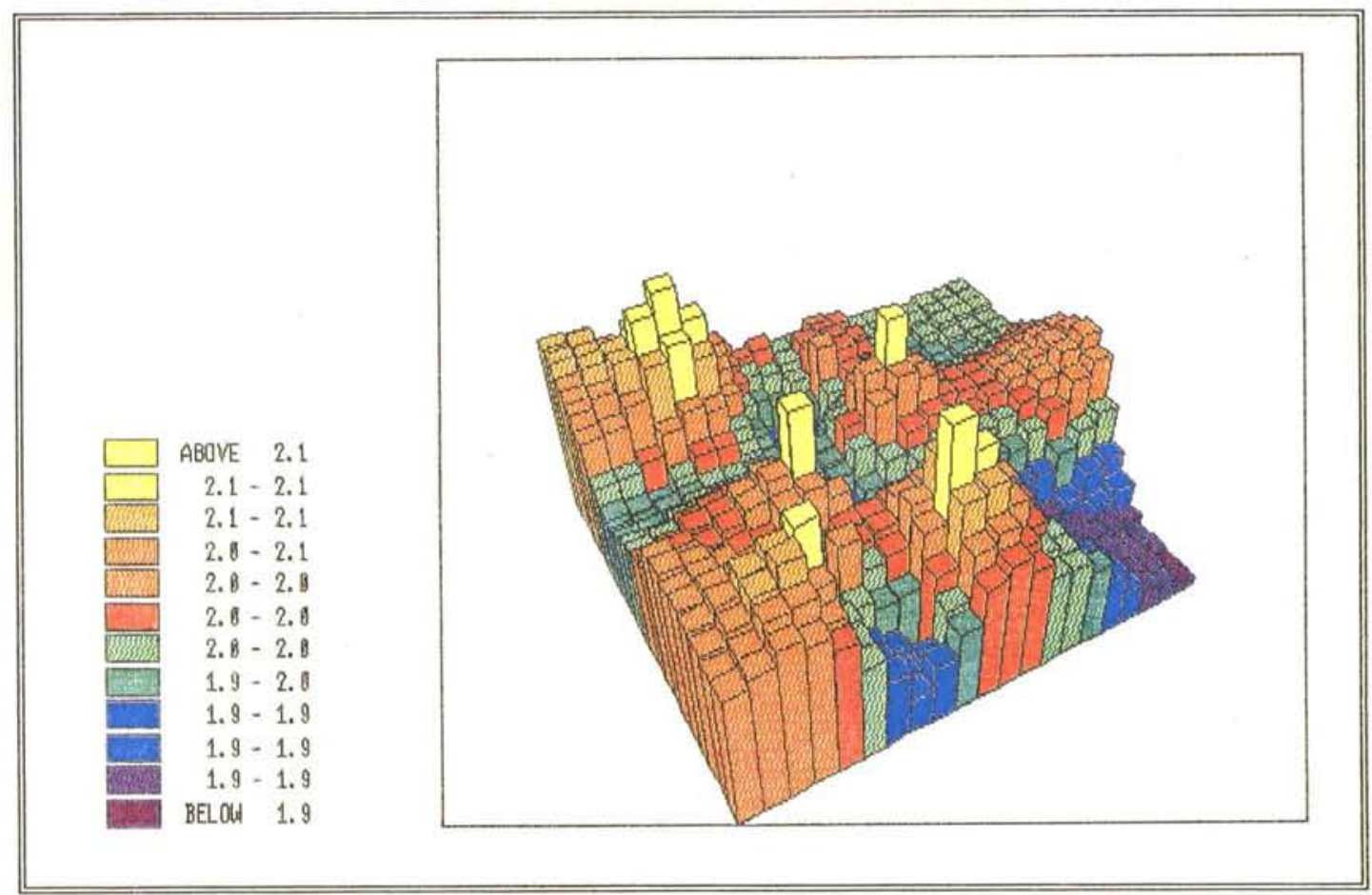

3b. Gráfico de puntos bidimensional interpolado

ISSN: 1133-4525 ISSN-e: 2255-3924 


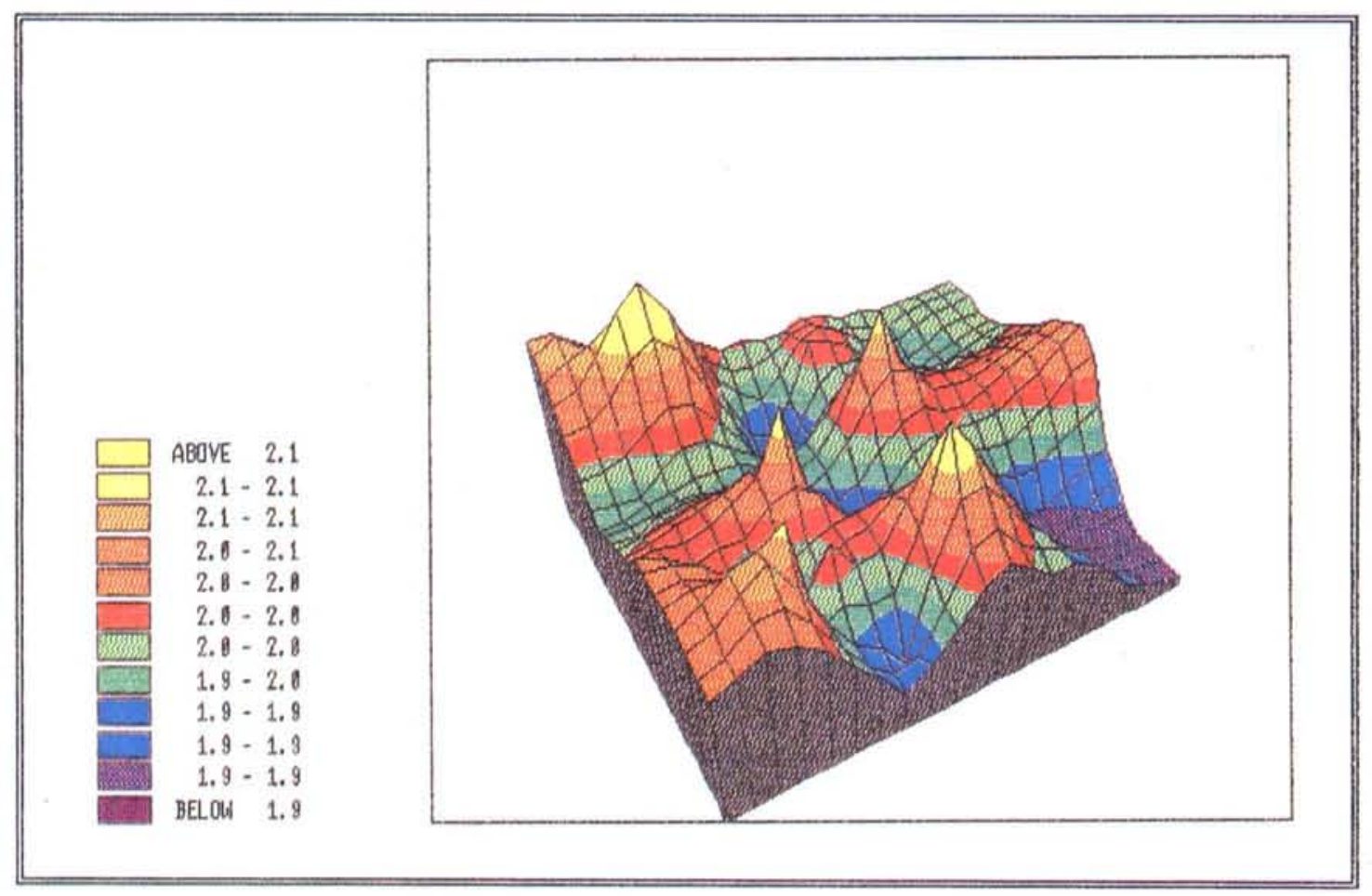

Gráfico de contornos interpolados tridimensional

cms. de grosor (ver leyenda). El gráfico resulta poco más expresivo que un dibujo de campo. En el segundo (Figura 2b), en cambio, la interpolación de la información produce una imagen mucho más expresiva: ahora podemos interpretar "areas" y no "puntos"; en este caso concreto no parece definirse ningún patrón aparente en la distribución del grosor de la cerámica.

Una variante del primer gráfico (Figura 3a) nos muestra los valores estudiados en columnas de tamaño proporcional semejantes a las empleadas en diagramas de barras, mientras que el siguiente (Figura 3 b) es una versión interpolada del mismo, de nuevo más explícita. El último de los gráficos (Figura 4) es un mapa de contornos interpolados tridimensional donde altura y color se relacionan proporcionalmente (menos altura-tonalidad oscura, más altura-tonalidad clara).

La cuestión de la interpretación de los gráficos permanece naturalmente sujeta al conocimiento arqueológico del fenómeno; en este caso, el software utilizado ha facilitado simplemente un instrumento eficaz de observación del fenómeno micro o semi-micro espacial. Si se ha efectuado un registro adecuado sobre el terreno, con la ayuda de un sistema como UNIMAP se puede observar gráficamente el funcionamiento espacial de cualquier variable a nivel micro, sin necesidad de recurrir a procedimientos mas costosos como reproducir íntegramente esta distribución en el suelo de un estudio.

\section{II.2. Gráficos a escala macro}

Si en términos generales los ochenta fueron los años de la consolidación de las aplicaciones informáticas en Arqueología, ahora aparecen predicciones sobre el papel relevante que pueden tener los Sistemas de Información Geográfica (SIG) tanto en el diseño de la investigación arqueológica a nivel 
macro como en la gestión del patrimonio arqueológico. A pesar del hecho de que diferentes aproximaciones han enfatizado diferentes aspectos de los SIG (Cowen, 1988), básicamente éstos pueden ser definidos como bases de datos espacialmente referenciadas provistas de medios sofisticados para la entrada, manipulación, análisis y salida de datos geográficos (Burrough, 1989. Green, 1990. Wansleeben, 1988), bajo los principios generales de SGBD (Farley, 1990. Elmasri, 1989. Frank, 1988). En realidad, estudios espaciales y estadísticos encaminados a descubrir las tendencias predominantes en los datos (Hodder-Orton, 1976. Shennan, 1988) han sido desarrollados en Arqueología desde hace bastante años, asi que los SIG no aportan nada nuevo al respecto. Es básicamente la integración de esos métodos con procedimientos automáticos de generación de gráficos lo que convierte a los SIG en un instrumento extraordinario de inmediata aplicación en Arqueología.

Los requerimientos fundamentales de un SIG arqueológico son complejos:

- Cantidades masivas de información espacial, incluyendo datos paleoambientales de buena calidad, ambos necesariamente productos de años de investigación.

- Información cartográfica digitalizada y datos de detección remota, asimismo costosos y no siempre disponibles.

- Finalmente, hardware y software complejos (Zubrow, 1990 Madry, 1990), que a su vez requieren considerables inversiones iniciales así como personal informático especializado.

En el momento presente la Arqueología andaluza cuenta con un volumen de información paleogeográfica publicada en general limitado, aunque por otra parte, la Agencia de Medio Ambiente trabaja desde hace varios años en la digitalización de información geográfica moderna (Barragán-Moreira, 1990. Rosa, 1987) susceptible de ser contrastada con datos arqueológicos, sea con propósitos experimentales sea para planificar la gestión del patrimonio histórico-arqueológico.

En el ejemplo de aplicación aquí expuesto se han tomado como base una serie de datos sobre tumbas individuales del SO peninsular del periodo 1500-1100 a.C. y datos sobre la potencialidad agrícola actual de Andalucía Occidental (Rosa, 1987) y el sur de Portugal (Soares, 1983).

La información cartográfica se ha digitalizado por medio de AutoCAD (AUTODESK, 1989). AutoCAD, como es bien sabido, es un complejo sistema de diseño asistido en cuya descripción no es necesario entrar aquí. Baste decir que su utilidad general para aplicaciones arqueológicas es considerable, si sólo porque su entidad conceptual más básica es una bien conocida en Arqueología: el estrato o capa (en cierto sentido el equivalente de lo que en la jerga de SIG, y a escala regional, se denomina "cobertura"). Cualquier combinación de las entidades gráficas que soporta AutoCAD (puntos, arcos, polilíneas, líneas, círculos, elipses, anillos, etc.) puede ser superpuesta a otra en estratos a los cuales se pueden especificar atributos tales como colores, nombre o tipos de línea, de manera que el sistema se convierte en el soporte ideal para almacenar información arqueológica espacial simulando su diacronía.

Cada capa/cobertura es exportada desde AutoCAD como fichero ASCII en formato vector usando la rutina ACDTOIDR del SGI para ordenadores personales IDRISI (Eastman, 1990) utilizado en el experimento. Cada entidad geográfica relevante recibe un número de identificación único, se importa en IDRISI, y entonces se crea una imagen raster del dibujo digitalizado. IDRISI es un popular SIG para PCs que provee un módulo central entrada, almacenamiento y recuperación de datos, dos módulos analíticos (uno de SIG y otro de estadística espacial), un módulo de procesamiento de imagen, y un módulo para transferencia de datos que le hace considerablemente compatible con otros SIG.

En este caso se han exportado cuatro capas desde AutoCAD, cada una delimitando el territorio perteneciente a cada categoría de potencialidad agrícola a escala 1:1.000.000, y luego se ha atribuido a 
Fig. 5 Gráficos Idrisi

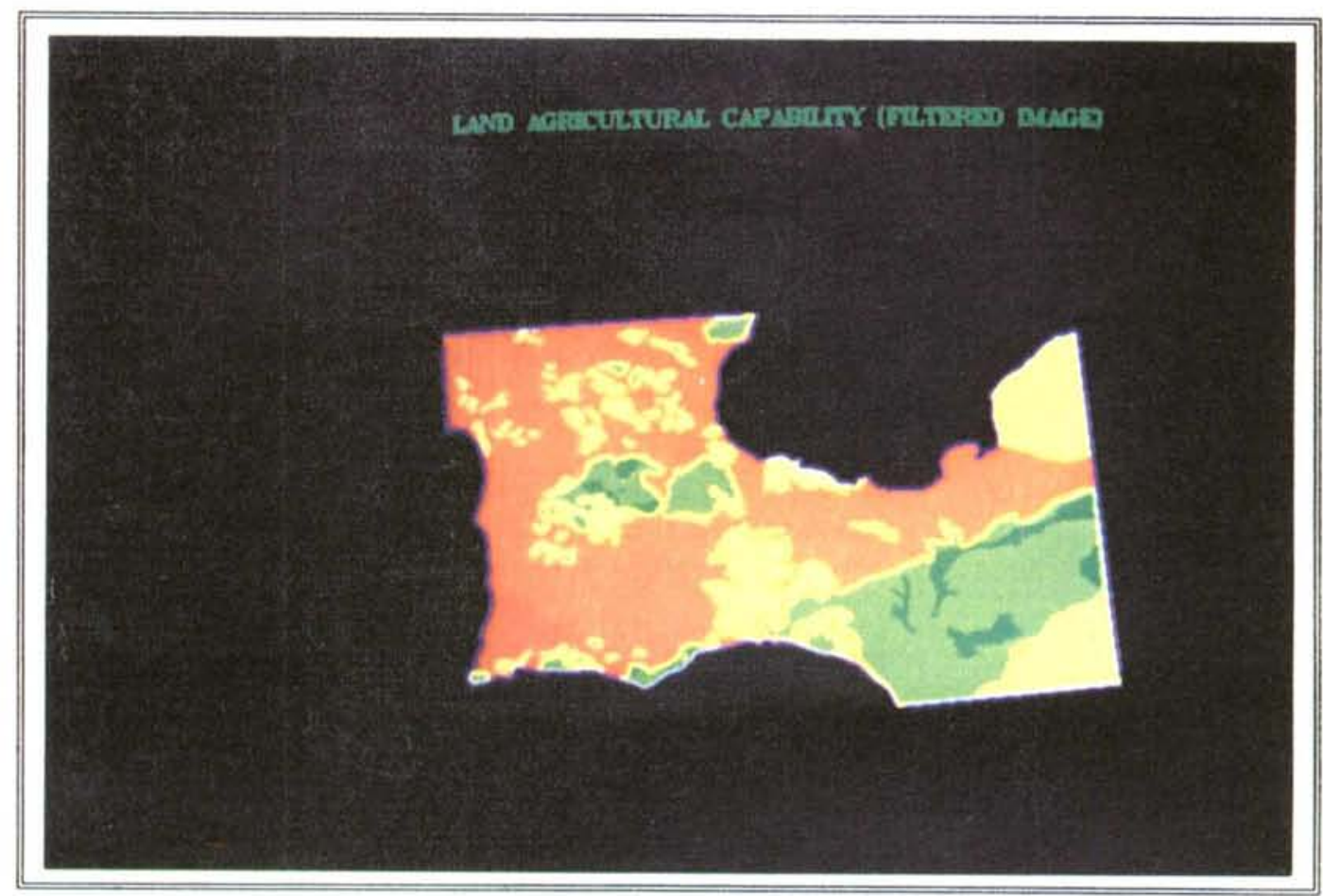

SW Peninsular. Potencialidad agricola del suelo

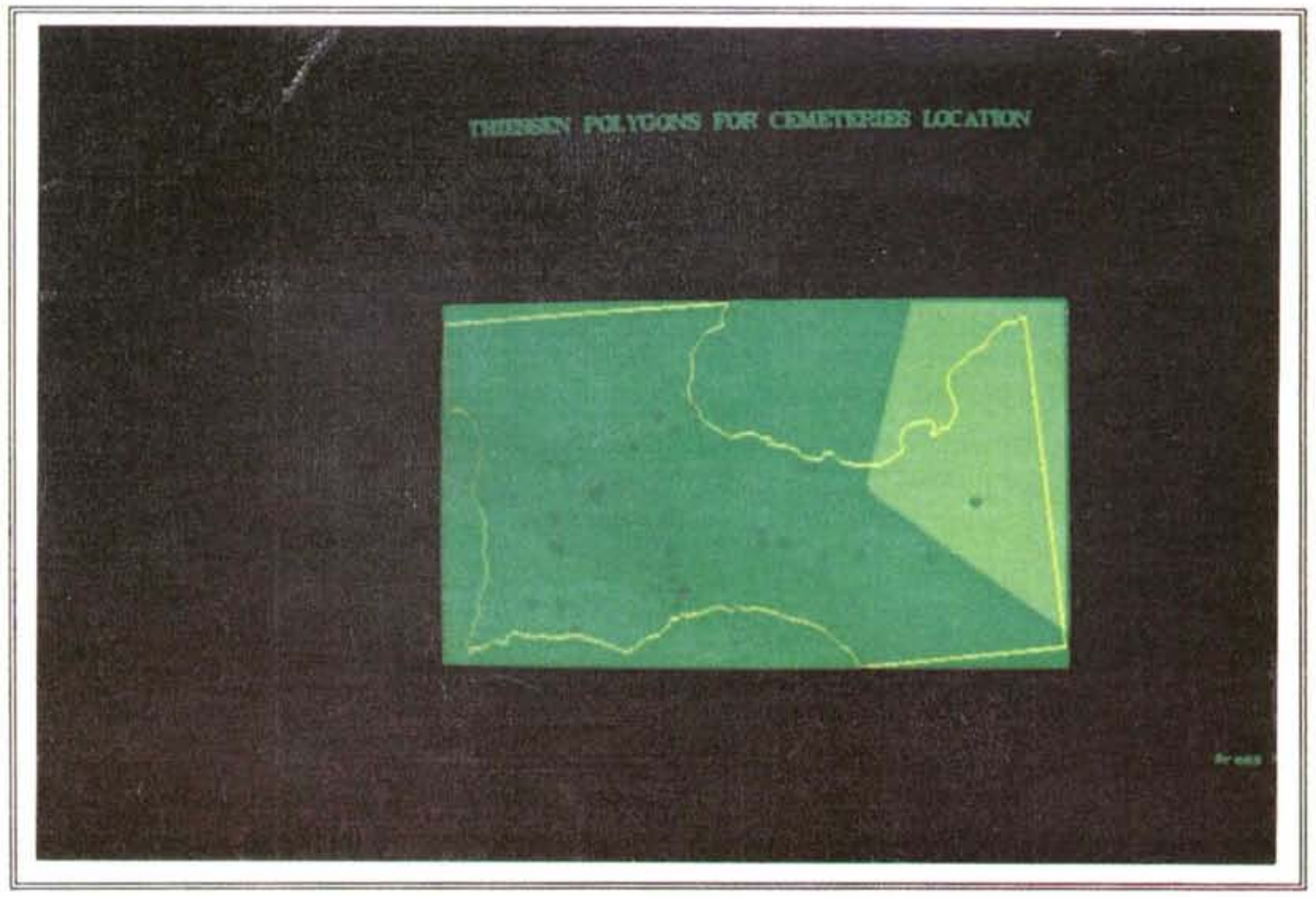

SW Peninsular. Distribución necropolis 1500-1100 a.C. 
cada una un coeficiente de 1 a 4 de acuerdo con la categorización básica empleada por los geógrafos en este respecto. Asimismo se ha exportado desde AutoCAD una capa con la situación geográfica de las necrópolis correspondientes incluidas en el estudio, y luego se ha manipulado la misma, atribuyéndose a cada necrópolis una serie de valores de acuerdo con unas variables relacionadas con la cantidad promedio de diversos artefactos por tumba. El propósito del experimento es investigar el coeficiente de correlación existente entre las variables arqueológicas (dependientes) y la capacidad agrícola del suelo (variable independiente). En la Figura 5 se observan ambas imágenes por separado: la superior corresponde a la imagen digital filtrada de potencialidad agrícola en el SO de la Península Ibérica mientras que la inferior presenta la localización de las necrópolis. La superposición de las mismas genera una serie de salidas numéricas no incluidos aquí que en general muestran la existencia de una correlación positiva alta entre las variables.

Independientemente del propósito específico del caso traido como ejemplo, es de destacar la posibilidad que ofrecen los SIG de investigar de forma automática la interacción medio-cultura arqueológica a escala regional. Mediante éstos, el marco físico, eterna "Introducción" inerte de los estudios arqueológicos tradicionales, pasa a ser un conjunto más de variables cuya relación dialéctica con las formaciones sociales primitivas puede expresarse gráficamente con considerable ahorro de tiempo y energía.

\section{MUSEOS Y DIVULGACION}

Una parte esencial de la Arqueología es aquélla en la que la disciplina devuelve a la sociedad en forma de conocimiento las inversiones humanas y materiales que la sociedad ha hecho através de ella para conocer y entender su pasado. Como cualquier otra ciencia social, la Arqueología no es para los especialistas, no es una caja negra donde sólo operan iniciados, sino que debe ser una caja transparente a través de la cual la sociedad mira hacia su propia identidad en el pasado. Los museos arqueológicos cumplen la función de ser esa caja transparente y accesible donde los individuos adquieren información sobre el pasado a través de la documentación arqueológica, de forma que en tal marco la investigación constituye una prioridad secundaria y queda relegada a un segundo plano. Si la informática se está imponiendo rápidamente como un instrumento esencial de racionalización del registro arqueológico y automatización de su análisis estadístico, en un proceso que nos llega con relativo retraso con respecto otros paises, parece que nuestros museos arqueológicos se muestran renuentes a asumirla como un intrumento de divulgación y enseñanzà de efectividad ya contrastada.

Entre la necesidad de renovar conceptualmente los museos andaluces de Arqueología y el potencial de los sistemas arqueológicos de información existe un nexo, lo que podríamos llamar el interfaz social de la Arqueología o una Arqueología "virtual", como ya ha sido definida a partir del concepto de "Realidad Virtual" (Rheingold, 1991). En general, podemos definir la "virtualidad" arqueológica como un nuevo enfoque del registro, estructuración, análisis, interpretación y difusión de los datos arqueológicos a través del uso de hipertextos y software para modelado sólido (Reilly, 1991). El concepto es laxo por su propia naturaleza, y puede perfectamente incluir otro tipo de aplicaciones gráficas computerizadas, pero sobre todo nos interesa extraer la idea de que se trata de una aproximación eminentemente gráfica, visual e intuitiva a los problemas arqueológicos que la hace especialmente adecuada para convertirse en el vehículo de difusión de nuestro conocimiento arqueológico del pasado, en un vehículo educativo. 


\section{III.2. Modelado Solido}

El modelado sólido constituye uno de los más recientes campos de experimentación en informática, una sugerente área de investigación que ya ha generado algunas aproximaciones arqueológicas experimentales. Básicamente envuelve la simulación computerizada de la realidad por medio del uso de entidades tomadas de la Geometría Constructiva Sólida. Esas entidades,denominadas "primitivos", son cubos, conos, esferas, elipses, cilindros, planos, cuñas, etc. Combinando estas entidades con una serie de operaciones elementales tomadas de la teoría de conjuntos mediante un lenguaje de programación de núcleo reducido se han generado simulaciones básicas de edificios, pinturas y entidades físicas y biológicas tales como átomos o proteínas, por ejemplo.

Los sistemas de modelado sólido contienen asimismo numerosas propiedades que permiten al usuario producir efectos visuales especiales con los cuales incrementar el realismo de las reconstrucciones tridimensionales. Se trata, por ejemplo, de efectos de iluminación o sombreado, fuentes de luz múltiples, cualidades superficiales o perspectivas.

El sistema WINSOM (WInchester SOlid Modeller) (Watson, 1989) es un programa de modelado sólido de gráficos desarrollado desde 1984 por el Centro Científico de IBM para el Reino Unido. Escrito en PASCAL/VS, versión 2.2 es considerado por el momento un producto experimental no comercializado. El programa soporta los primitivos habituales, bloques, conos, cubos, cilindros, elipsoides, planos, esferas y cuñas, y una serie de operaciones con la que pueden ser manipulados: DIFF (sustracción del segundo objeto del primero), INT (intersección de dos objetos), SDIFF (diferencia simétrica de los puntos dentro del primer objeto y del segundo objeto) y UNION (combinación de dos objetos, mostrando las dos partes no comunes). Asimismo, contiene una serie de operadores para localizar y mover dichas entidades: ROTATE, SCALE, YROT, XROT y ZROT. Finalmente, la posición relativa y tridimensionalidad de los objetos se refuerza con sentencias como VIEW, AMBIENT, BACKGROUND, CAMERALIGHTS, OBJECTLIGHTS, REFLECT, SHADOWS, COLOUR o SCALE

La sentencia SIZE controla la resolución de la imagen, es decir, especifica el tamaño de los pixels que constituyen cada entidad. Contra mayor el valor incluido en la sentencia, menor el tamaño del pixel, y consecuentemente más alta la resolución. El manejo de buenas resoluciones requiere grandes memorias y más tiempo de trabajo de la CPU, de manera que la reproducción de imágenes complejas con buena resolución puede tomar muchos minutos.

Una vez que un modelo ha sido creado se pueden obtener diferentes puntos de vista de la escena, así que, por ejemplo, en la reconstrucción de un edificio es posible obtener una perspectiva exterior del mismo, y, a continuación, "navegar" hacia su interior obteniendo una vista desde dentro hacia afuera a través de una ventana. De hecho ya se han realizado aplicaciones arqueológicas de WINSOM que demuestran las posibilidades del modelado sólido en divulgación, publicación, simulación o incluso investigación pura. En la reconstrucción de restos arquitectónicos a través de la documentación arqueológica ya se han realizado experimentos satisfactorios con estructuras subterraneas no excavadas (y por tanto ocultas a los ojos del visitante) pero bien conocidas en casas romanas de Pompeya, o con grandes edificios como la catedral anglosajona de Winchester (Reilly, 1991. Delooze, 1991). Asimismo, WINSOM ha sido utilizado para representar la distribución estadística de ciertos tipos cerámicos de acuerdo con los datos obtenidos de prospecciones electromagnéticas (Reilly-Shennan, 1990).

Sin embargo, independientemente de su utilidad para representar tridimensionalmente gráficos estadísticos, donde el modelado sólido, y en concreto el caso del sistema WINSOM que aquí he traido como ejemplo, tienen un mayor potencial arqueológico es en el campo de la recreación de estructuras 
constructivas con propósitos divulgativos y educativos. La accesibilidad de la información arqueológica al visitante de un museo se multiplica infinitamente cuando, en lugar de ofrecer a éste una sesión de planos, artefactos y fotografias se le da la posibilidad de contemplar una necropolis prehistórica "virtual".

En las Figuras 7 y 8 se ofrece un modelo tridimensional muy simple y elemental de dos de los túmulos (aquí unidos arbitrariamente) de la necrópolis tartésica del siglo VII a.C. de Setefilla (Lora del Río, Sevilla) (Aubet, 1975). El conjunto de veintiuna sentencias que permitieron a WINSOM crear este modelo esquemático es mostrado en la Figura 6. Entre asteriscos, a la izquierda del listado, figura como comentario el nombre del elemento al que se refiere la sentencia. A continuación se indica el tipo de primitivo utilizado, la operación, la indicación del tamaño (tres primeras cifras entre paréntesis), la localización en la escena (segundo grupo de tres cifras entre paréntesis), y ,finalmente, el color seleccionado para ese elemento. Las dos últimas sentencias marcan la perspectiva, es decir, la situación del observador en los ejes X e Y expresada en grados.

La imagen (las impresiones tomadas directamente de la pantalla desmerecen considerablemente el grado de resolución de una pantalla IBM 5080) pretende mostrar de forma aproximada el aspecto de los túmulos en un estadio imaginario de su excavación, puesto que uno de los aspectos más relevantes de la misma fue su planteamiento (en lugar de excavar una cuadrícula desde la parte superior del túmulo hacia abajo, donde suele encontrarse la cámara, la profesora Aubet lo excavó por cuadrantes). El túmulo de la izquierda ha sido cortado por la mitad por un cubo para mostrar las urnas de incineración que en él fueron halladas (cilindros rojos pequeños), mientras que en el de la derecha sólo un cuarto ha sido excavado, hallándose algunas losas de piedra.

Naturalmente, la escena debería haber sido mucho más detallada para haber sido considerada arqueológicamente válida (y didáctica) pero los principios sobre los que funciona la técnica son perceptibles, y por tanto el ejemplo da la medida de lo que una nueva orientación museística podría proporcionar.

Fig. 6. Gráficos Winsom

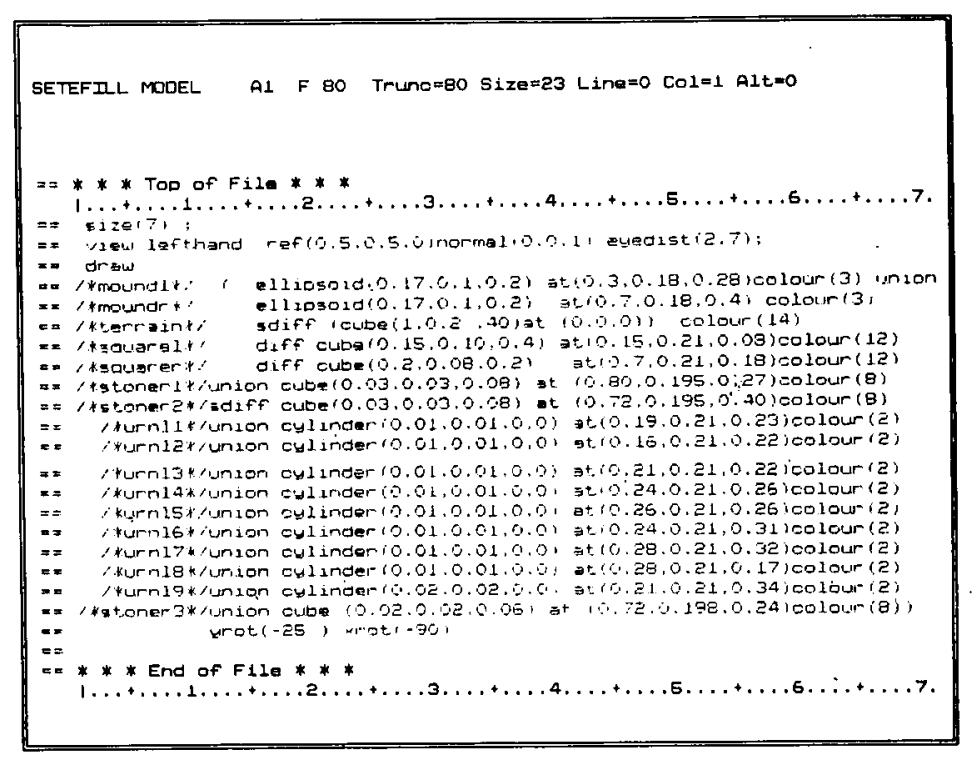

Conjunto de sentencias Winson de la imagen 
Fig. 7 Gráficos Winsom
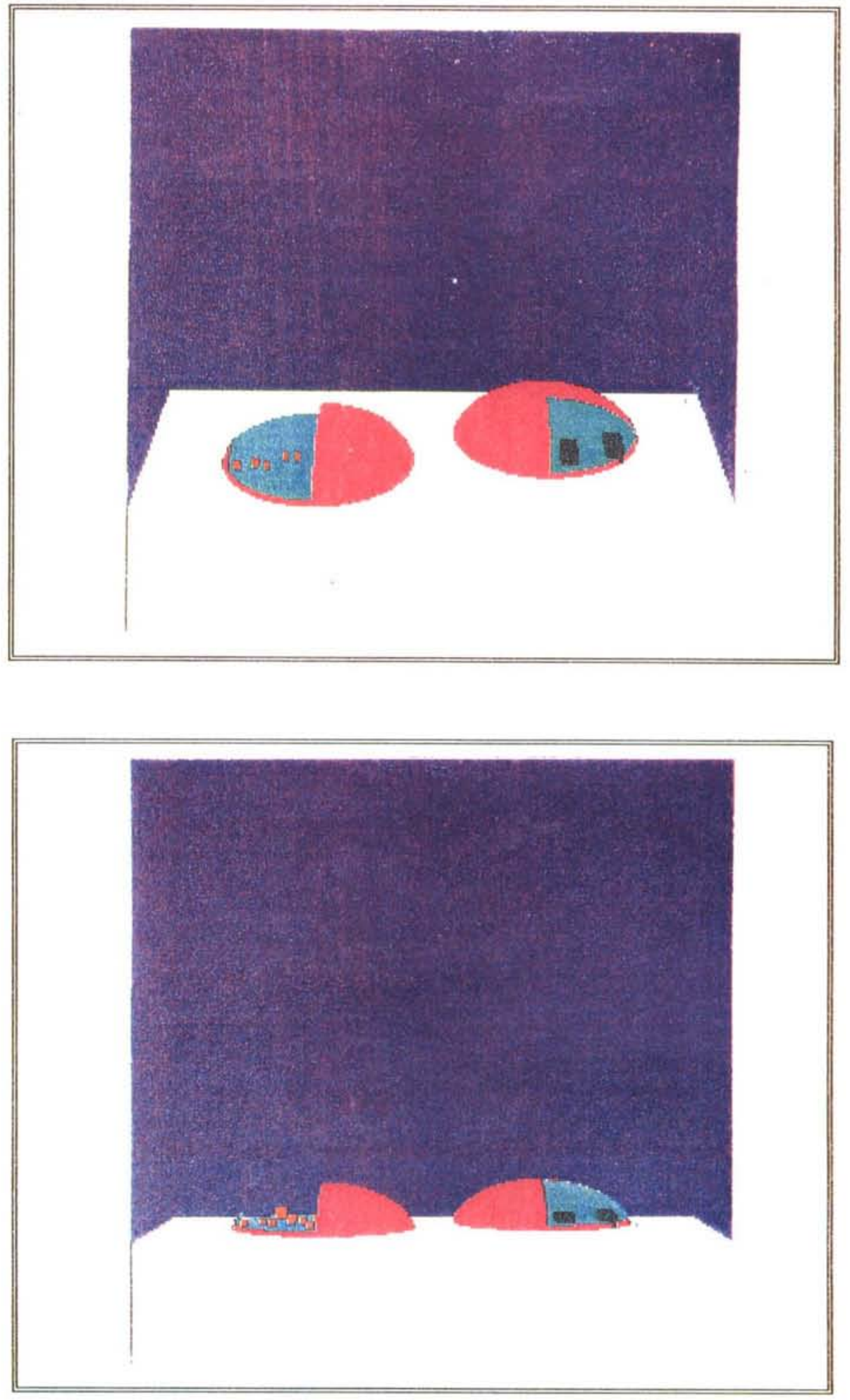

Baja resolución 
Fig. 8 Gráficos Winsom
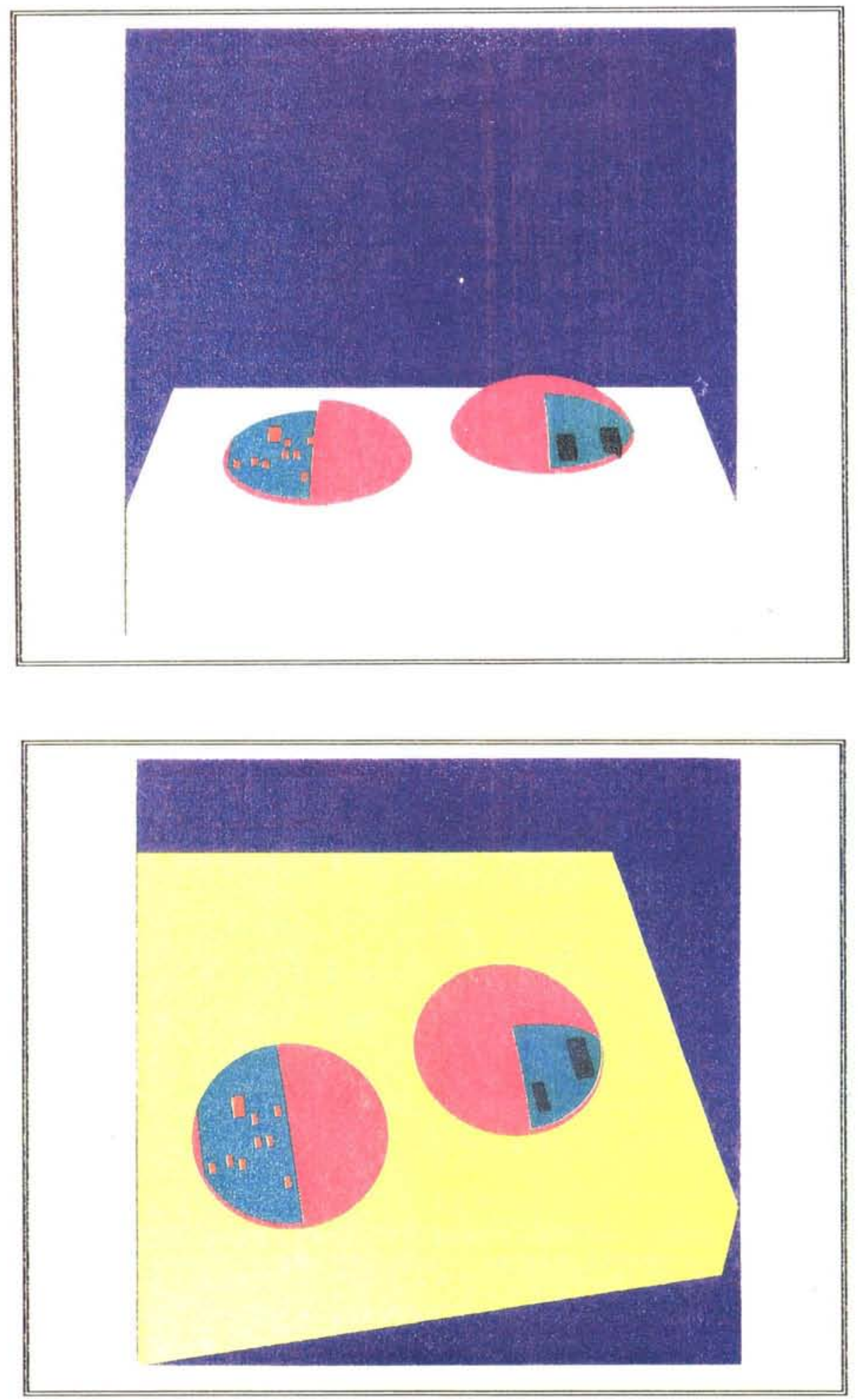

Alta resolución 


\section{III.3. Hipertextos}

Los sistemas de hipertexto están básicamente concebidos para almacenar texto e información gráfica, combinarla y mostrarla en un interfaz altamente "user-friendly". Es decir, pueden ser considerados libros electrónicos no secuenciales en oposición a los libros normales (Nielsen, 1990). Un hipertexto tiene dos partes fundamentales: una base de datos que almacena la información a ser mostrada, y el interfaz (texto más gráficos más sonido mas video). Aquí se insiste en su utilidad como instrumento didáctico en museos arqueológicos, pero naturalmente aquella no está en absoluto restringida a este campo particular, puesto que ya se han producido hipertextos arqueológicos con propósitos docentes a nivel universitario (Orton-Grace, 1991) o simplemente experimentales (Barceló, 1991).

Existen notables diferencias entre los numerosos sistemas de hipertexto disponibles en el mercado, Notecard y KMS para estaciones de trabajo, Hyperties, Guide y Hyperpad para compatibles IBM, y Hypercard de Apple, etc., tomando ventaja probablemente este último. Para ilustrar la aplicabilidad de estos sistemas en Arqueología se ha construido un documento en HYPERPAD, de nuevo tomando como base los datos de una de las campañas de excavación en Setefilla (Aubet, 1975). Este sistema proporciona un entorno bastante sencillo de manejo para mostrar información textual de forma aprehensible. Presenta un serio handicap, cual es la imposibilidad de combinar gráficos con el texto, y ello le hace claramente inferior en prestaciones a, por ejemplo, Hypercard. No obstante nos servirá para comentar brevemente los principos en que se basa este tipo de aplicaciones.

Las entidades básicas manejadas son: campos, botones, fondos y páginas. Los campos contienen el texto propiamente dicho, sea fijo en la pantalla, sea en una ventana "enrollable", mientras que los botones pérmiten al usuario navegar a través del documento de una forma más o menos flexible dependiendo del criterio empleado por el diseñador. La entidad básica es la página (conteniendo botones y campos), así que un documento se define propiamente por su número de páginas.

El documento cuyo menú principal se muestra en la Figura 9 cuenta con dieciseis páginas distribuidas en varios bloques: un bloque de presentación del documento y de la cultura tartésica, un segundo bloque constituido por un menú principal que conduce a cinco posibles opciones (estructuras arquitectónicas, artefactos, paleoambiente, antropología y bibliografía), cada una constituida por dos "pads", y un último bloque de opciones de apoyo (los tres botones inferiores de la pantalla). El propósito específico de un documento de este tipo es que el visitante del museo elija y obtenga interactivamente información arqueológica textual y gráfica. La posibilidad de incluir documentos de vídeo, fotos y reconstrucciones tridimensionales (modelado sólido) en un hipertexto (sólo para proyectos de financiación privilegiada) da una nueva dimensión a la exposición de la información de un museo (Martlew, 1990. Mayton, 1990). No en vano se ha sugerido que uno de los principales campos de desarrollo de la Arqueología de los noventa será la educación (Orton, 1991).

\section{UNIVERSIDAD Y EDUCACION}

Si la enseñanza especializada de la Arqueología con propósitos profesionales en la Universidad ha comenzado a ser objeto de pública discusión recientemente (Austin, 1987. Barandiarán et alii, 1991. Champion, 1991. Ruiz, 1991), las perspectivas de una formación informática básica dentro la misma parecen aún un tanto desalentadoras, incluso desde departamentos reputados como progresistas en países de mucha mayor tradición al respecto que España:

"In most departments the syllabus remains doggedly devoted to regional and chronological appro- 
Fig. 9. Gráficos Hyperpad

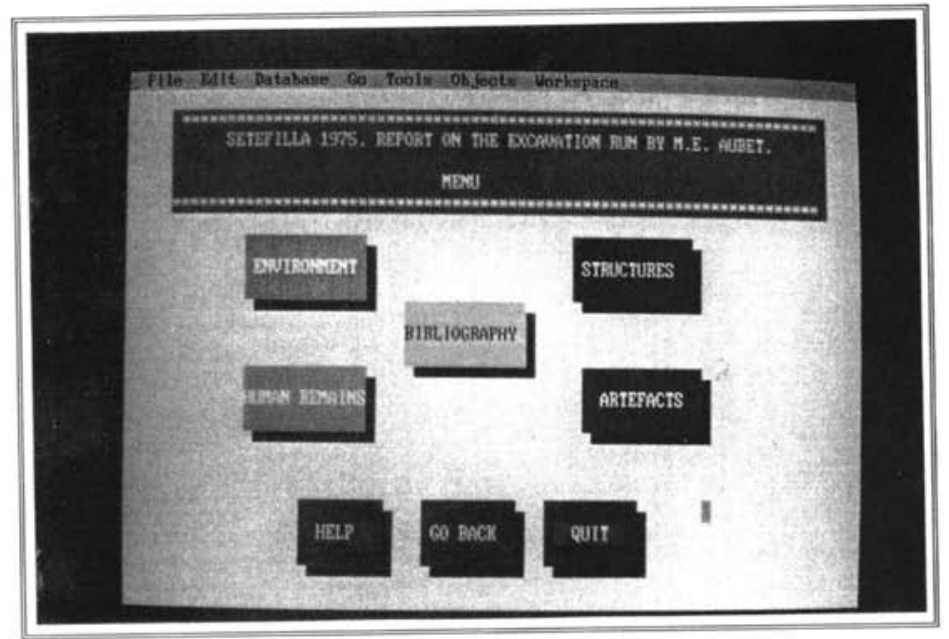

9a. Menú principal del documento Setefilla.Pad

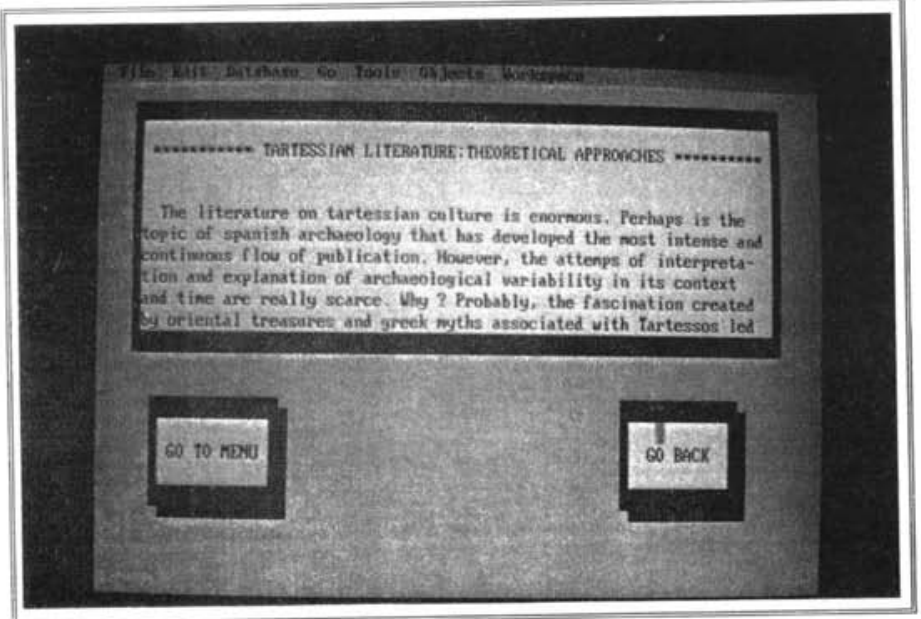

9b. Sección "Bibliografía" del documento

ISSN: 1133-4525 ISSN-e: 2255-3924 
aches to Archaeology (...)Some departments have responded to recent advances by introducing courses in such fields as computing or quantitative methods, but in some places, I suspect, the teaching of courses on the History, Methods and Principles of Archaeology carries low priority and a low status..." (Champion, 1991)

Una valoración de la relevancia de las nuevas tecnologías y marcos teóricos en los departamentos universitarios de Arqueología escapa al propósito general de este artículo, más interesado en sugerir cómo los ordenadores pueden integrarse próximamente en la docencia universitaria.

Por una parte, en términos generales, sería deseable que los estudiantes de Arqueología recibieran una formación general básica en gestión informática de datos. Seguir ignorando que los ordenadores no son ya una cuestión de especialización sino un instrumento de trabajo tan esencial como un bolígrafo o una pala no hace demasiado por el futuro de la disciplina. Obviamente no se trata de dar a los estudiantes de primer y segundo ciclo una especialización integral en aplicaciones informáticas, sino conseguir de ellos una serie de conocimientos mínimos que, de hecho, van a necesitar en cualquier faceta de su vida profesional. La estructura de esta introducción básica al manejo informático de datos, planteada hace años en EEUU (Cline, 1968) ha sido recientemente discutida por varios autores (Richards-Ryan, 1985. Richards, 1985. Greene, 1985) y podría resumirse en tres puntos principales:

- Comprensión básica de los componentes hardware y software de un sistema informático.

- Capacidad de estructurar y codificar los datos arqueológicos de forma apropiada para su análisis estadístico informatizado.

- Buen manejo de aplicaciones tales como bases de datos, hojas de cálculo, paquetes estadísticos y procesadores de textos.

La simple introducción de conceptos informáticos en las materias metodológicas universitarias podría ser considerada un gran avance, puesto que proporcionaría a los estudiantes una perspectiva del potencial de los ordenadores en su trabajo futuro. Considero un grave error y una hipoteca sobre el futuro de la disciplina creer que la informática es otra más de la larga lista de las mal llamadas "Ciencias Auxiliares" y reservar consecuentemente su utilización en la Universidad a una secta de iniciados. En la actualidad los departamentos universitarios andaluces de Arqueología cuentan con una notable infraestructura de apoyo tanto de hardware como de software o de asesoramiento profesional por parte del Centro de Informática Científica de Andalucía (CICA, 1990. CICA, 1991) que les permite utilizar un amplio abanico de programas sin ningún costo adicional.

Existe un segundo aspecto de la enseñanza de la Arqueología en la Universidad en la cual los ordenadores ya han empezado a tomar parte: el entrenamiento de los estudiantes para el trabajo de campo por medio del uso de simuladores de excavación. El programa SYGRAF (Wheatly, 1991), desarrollado como una versión transformada del proyecto SYASS (Southampton York Archaeological Simulation System) (O’Flaherty, 1988. Rahtz, 1989) es un programa de simulación consistente en una fuente (un yacimiento) y un programa (rutinas de excavación), independientes el uno del otro. Un yacimiento se compone de dos tipos de entidades: contextos (unidades estratigráficas de cualquier naturaleza) que se representan gráficamente como entidades multipunto, y hallazgos (artefactos y ecofactos), considerados entidades de punto simple. Ambos tipos de entidades se almacenan físicamente en una serie de tablas DBF.

En realidad, independientemente de la estructura básica del sistema, lo que el usuario (excavador en 
este caso) ve en la pantalla del ordenador es una superficie verde cuadriculada que representa el yacimiento a ser excavado, así como un menú con una serie de opciones referidas a los cortes a abrir y a las herramientas a utilizar. Como un ejercicio metodológico más, el estudiante encara la responsabilidad de diseñar una estrategia equilibrada entre un presupuesto específico (corto normalmente) y la necesidad de responder a una serie de preguntas sobre la naturaleza del yacimiento; es decir, se enfrenta a una situación que intenta reproducir lo más fielmente posible la realidad profesional. Las implicaciones pedagógicas ya han sido sugeridas por los propios diseñadores del sistema (Wheatly. 1991) tras la primera aplicación del mismo como parte de un curso de metodología arqueológica y no es necesario insistir aquí en ello.

Desde el punto de vista de la construcción de gráficos arqueológicos computerizados, SYGRAF plantea la necesidad de construir en aquellos departamentos que hipotéticamente quieran incluirlo como instrumento docente, una "biblioteca" de yacimientos que puedan ser excavados por sucesivas promociones de estudiantes. La naturaleza "source-based" del sistema permite construir yacimientos sin que ello requiera modificar en absoluto el programa.

La Figura 10 muestra un ejemplo de yacimiento arqueológico preparado para ser excavado en SYGRAF que servirá para examinar la relativa sencillez de la construcción "ad infinitum" de esa biblioteca de yacimientos (para mantener la consistencia con el ejemplo anterior se han preparado los dos mismos túmulos de Setefilla, ahora para ser "excavados"). Como base se ha utilizado una planta de las estructuras del yacimiento digitalizada de nuevo por medio de AutoCAD. En este caso, utilizando el modo TABLET se han digitalizado dos capas: la primera representa el perímetro de la zona excavada por la Profesora Aubet y los contextos (polilíneas), y el tercero los artefactos (anillos - sólamente se han incluido las urnas de incineración). Una vez completado el mapa, la información se transfirió desde un archivo DXF de AutoCAD a DBase III+ utilizándose para ello un programa escrito en PASCAL. Los contenidos de los ficheros TXT resultantes (BOX, CONTENTS y FINDS) son entonces añadidos a las tablas SYGRAF correspondientes utilizando el modo comando de DBase III +. La entrada del resto de la información requerida por SYGRAF (colores y símbolos que representarán los artefactos, por

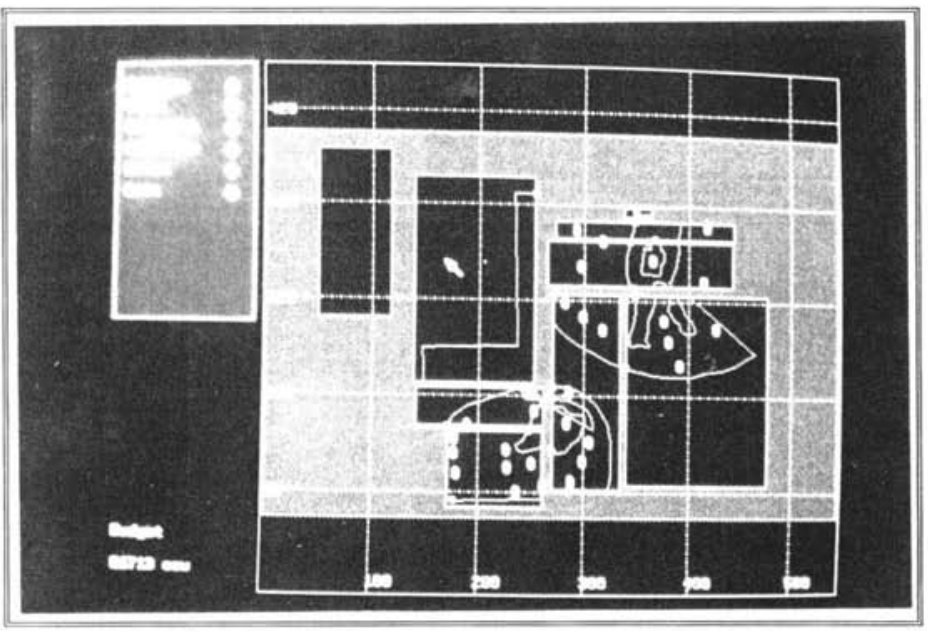

Fig. 10. Gráficos Sygraf.

Planta digitalizada de dos "rümulos" de Setefilla dispuestos para ser "excavados" mediante Sygraf.

ISSN: 1133-4525 ISSN-e: 2255-3924

http://dx.doi.org/10.12795/spal.1992.i1.02 
ejemplo) se hace a mano directamente en la base de datos.

El proceso de crear más yacimientos para que los estudiantes los excaven (quien sabe si incluso planteando una mejor estrategia que sus excavadores originales) se vuelve rápido y sencillo una vez que se maneja con fluidez el software implicado en el proceso, lo cual convierte a SYGRAF en un método de simulación computerizada útil en la docencia de la Arqueología.

\section{CONCLUSION}

Se ha intentado mostrar el potencial de algunas piezas de software para la generación de gráficos apropiados en cada uno de los ejes de desarrollo de la Arqueología actual (museos, universidad y unidades administrativas). Una disciplina tan estrechamente vinculada a la Arqueología en su evolución reciente como la Geografía (Wagstaff, 1987) ha captado rápidamente la importancia estratégica de la automatización del manejo de datos generando un marco nuevo y original de análisis espacial cual es un SIG. Allí donde la gestión computerizada de la información arqueológica se inició mucho antes que en España (Flude, 1980. Hinchliffe-Jefferies, 1985. Dibble-McPherron, 1988) se ha demostrado que, aunque el proceso no está exento de considerables dificultades (Cooper, 1985), los resultados merecen el esfuerzo de renovación ante la alternativa de un auténtico colapso arqueográfico a corto plazo.

La evolución hacia una mayor eficacia, rapidez y economía en el manejo de la información no debe ser detenida por una errónea concepción "humanista" (entendido el concepto en su más estrecha y pobre acepción) de la Arqueología ${ }^{2}$. Desde un punto de vista epistemológico, la Arqueología asistida por ordenador no es ni mejor ni peor que la Arqueología no asistida por ordenador: los fundamentos teóricos que deben subyacer detrás de un proyecto de investigación arqueológica no tienen por qué verse afectados por los medios que se empleen para gestionar y analizar los datos.

El uso de gráficos computerizados representa sólo un apartado concreto de la demostrada utilidad de los ordenadores en el trabajo arqueológico: esperamos que con este trabajo se haya contribuido siquiera mínimamente a la extensión del uso de estos intrumentos de trabajo en una Arqueología andaluza que necesita seguir renovándose constantemente.

\section{BIBLIOGRAFIA}

ALCINA, J.(1975): "La Arqueología Antropológica en España: situación actual y perspectivas". En JIMENEZ , A. (Ed.): Actas de la I Reunión de Antropólogos españoles (Sevilla, 1973). Sevilla.

ARROYO, D.-LANTADA, M. T. (1990a): "Archaeological Computing in South-Western Europe (France, Spain, Portugal and Andorra)" En RAHTZ, S. P. (Ed.): Computers and Quantitative Methods in Archaeology. Proceedings of the 1989 CAA Conference (Birmingham, 1988). BAR International Series. Oxford.

ARROYO, D.-LANTADA, M. T. (1990b): Une biliographie sur l'application de l'informatique en l'Archeologie. Paris, Editions du CNRS.

ASPINALL, A. (1986): "Hard science: too hard for Archaeology?". En GINTLIFF, J. L.-GAPFNEY, L. F. (Eds.): Archaeology at the interface: studies in the Archaeology's relationships with History, Geography, Biology and Physical Sciences. BAR International Serie. Núm. 300. Oxford. 1986.

AUBET, M. E. (1975): La Necrópolis de Setefilla en Lora del Río (Sevilla) Barcelona. CSIC.

2. Efectivamente, “...los gráficos generados por ordenador (...) abren un gran número de posibilidades de investigación y simplificación en gran manera unas tareas que antes exigían mucho tiempo y dinero". (Schrodt, 1987). 
AUSTIN, D. (1987): "The future of Archaeology in British Universities" Antiquity. Núm. 61. London.

AUTODESK (1989): AUTOCAD Reference Manual. Exeter. Wheatons. 1989.

BARANDIARAN, I. et alii (1990): "Situación actual y perspectivas en docencia e investigación para el área de Prehistoria". En AAVV: Tendencias en Historia. Madrid. CSIC.

BARRAGAN, J. A.-MOREIRA, J. M. (1990): SINAMBA. Sistema de Información Ambiental de Andalucía. Sevilla. AMA.

BARCELO, J. A. (1988): "Introducción al razonamiento estadístico aplicado a la Arqueología: un análisis de las estelas antropomorfas de la Península Ibérica". Trabajos de Prehistoria. Núm. 45. Madrid.

BARCELO, J. A. (1991): "Programming an Intelligent Database in Hypertext" Computers and Quantitative Methods in Archaeology. Proceedings of the 1991 CAA Conference (Oxford, 1991). (En prensa).

BINFORD, L. R. (1962): "Archaeology as Anthropology" American Antiquity. Núm. 28.

BINFORD, L.R.- BINFORD, S. (1968): New Perspective in Archaeology. New York.

BURROUGH, P.A. (1986): Principles of Geographic Information Systems for land resources assessment. Oxford. Clarendon Press.

CHAMPION, T. (1991): "Theoretical Archaeology in Britain". En HODDER, I. (Ed.): Archaeological Theory in Europe: the last three decades. London.

CHOCLAN, C. et alii (1984): "Bases fundamentales para la elaboración de un modelo de fícha para prospección sistemática" Arqueología Espacila Núm. 1. Teruel.

CICA (1990): Boletín Número 1. Sevilla.

CICA (1991): Boletín Número 2. Sevilla.

CLARKE, D. L. (1968) : Analytical Archaeology. London. Methuen.

CLARKE, D. L. (1973): “Archaeology: the loss of innocence” Antiquity. Núm. 57.

CLINE, H. F. (1968): "Computer instruction for scholars in humanities" Computers and the Humanities. Vol. 3. Núm. 1, New York.

COOPER, M. (1985): "Computer in British Archaeology: the need for a national strategy". En COOPER, M. RICHARDS, J. (Eds.): Current Issues In Archaeological Computing. BAR International series. Núm. 271. Oxford.

COWEN, D. J. (1988): "GIS vs. CAD vs. DBMS: What are the differences." Photogrametric Engineering and Remote Sensing. Volumen 54. Núm. 18.

DELOOZE, K.-WOOD, J. (1991): "Furness Abbey survey project" En LOCKYERAR, K.-RAHTZ, S. P. (Eds.): Computer applications and quantitative methods in Archaeology. Proceedings of the 1990 CAA Conference (Oxford, 1990). BAR International Series. Núm. 565. Oxford.

DIBBLE, H. L.-McPHERRON, S. P. (1988): "On the computerization of archaeological projects" Journal of Field Archaeology. Volume 15.

DPUG: (1986): "Propuesta de un modelo sistemático de recuperación del registro arqueológico". Arqueología Espacial. Núm. 7. Teruel.

EASTMAN, I. R. (1990): IDRISI: A Grid-Based Geographical Analysis System. Worcester.

ELMASRI, R.-NAVATHE, S. (1989): Fundamentals of Database Systems. Redwood City.

FARLEY, J. et alii: (1990): "The archaeologist's workbench: integrating GIS, remote sensing, EDA and DMBS". En ALLEN, K. et alii (Eds.): Interpreting Space. GIS and Archaeology. London. Taylor and Francis.

FERNANDEZ, V. (1989): Teoría y Método de la Arqueología. Madrid. Síntesis.

FERNANDEZ, V.-FERNANDEZ, G. (1989): "La Informática en la Arqueología. Resultado de una encuesta". Revista de Arqueología. Núm. 97. Madrid.

FERNANDEZ, V.- FERNANDEZ, G. (Eds.). (1991): Aplicaciones Informáticas en Arqueología. Madrid. Universidad Complutense.

FLUDE, K. (1980): "Computing in the Department of Urban Archaeology". En STEWARD, D. D. (Ed.): Microcomputers in Archaeology. MDA Occasional Papers Núm. 4. Duxford.

FRAND, A. V. (1988): "Requirements for a DBMS for a GIS. "Photogrammetric. Engrineering and Remote Sensing. Vol. 54. Núm. 11. 1988. 
HINCHLIFFE, J.-JEFFERIES, J. S. (1985): “Ten years of data processing in the Central Excavation Unit". En COOPER, M.-RICHARDS, J.: A. (Eds.): Current Issues in Archaeological Computing. BAR International Series. Núm. 271. Oxford.

GREEN, S. W. (1990): "Approaching archaeological space”. En ALLEN, K. et alii (Eds.): Interpreting Space. GISand Archaeology. london. Taylor and Francis.

GREENE, K. (1988): "Teaching Computing to Archaeology students: an off-the-peg solution" Archaeological Computing Newsletter. Núm. 14. Stafford. Department of Computing. 1988.

HODDER. I. (1976): Spatial Analysis in Archaeology. Cambridge. University Press.

HODDER, I. (1976): Reading the past. Current Approaches to Interpretation in Archaeology. Cambridge. University press.

HODSON, F. R.-TYERS, P. A. (1988): "Data analysis for archaeologists: the Institute of Archaeology Packages". En RAHTZ, S. P. (Ed.): Computers and Quantitative Methods in Archaeology. Proceedings of the 1988 CAA Conference (Birmingham, 1988). BAR International Series. Núm. 446. Oxford.

LUCAS, J. M. et alii (1986): "Utilización del ordenador en el análisis microespacial" Arqueología Espacial. Núm. 7. Teruel.

MADRY. S. L. (1990): "The realities of hardware". En ALLEN, K. et alii (Eds.): Interpreting Space. GIS and Archaeology. London. Taylor and Francis.

MARTLEW, R. (1991): "Every picture tells a story: the archaeology disc and its implications" En LOCKYEAR, K.-RAHTZ, S. P. (Eds.): Computer applications and quantitative methods in Archaeology. Proceedings of the 1990 CAA Conference (oxford, 1990). BAR International Series. Núm. 565. Oxford.

MAYDOM, J.-TOREVELL, K. (1991): "Putting the video in the picture: an interactive video applications generator". En LOCKYEAR, K.-RAHTZ, S. P. (Eds.): Computer applications and quantitative methods in Archaeology. Proceedings of the 1990 CAA Conference 9Oxford, 1990). BAR International Series. Núm. 565. Oxford.

MONTERO, I.-MONTERO, M. A. (1984): "Análisis asistido por ordenador de yacimientos arqueológicos". Boletín de la Asociación española de Amigos de la Arqueología. Núm. 20. Madrid.

NIELSEN, J. (1990): Hypertext and Hypermedia. London. Oval Road.

NOCETE, F. (1989): El espacio de la coerción. la transición al Estado en las Campiñas del Alto Guadalquivir (España) 3000-1500 a. C. BAR International Series. Núm. 492. Oxford.

O'FLAHERTY, B. (1988): “The Southampton-York archaeological simulation system". En RAHTZ, S. P. (Ed.): Computers and Quantitative Methods in Archaeology. Proceedings of the 1988 CAA Conference (Birmingham, 1988). BAR International Series. Núm. 446. Oxford.

OLARIA, C.-GUSI, F. (1984): "Nuevos métodos de clasificación y catalogación aplicados al estudio tipológico de cerámicas prehistóricas: utilización del ordenador". Actas I Jornadas de Metodología de Investigación Prehistórica (Soria, 1981). Madrid. Ministerios de Cultura.

ORTON, C.-GRACE, R. (1990): "Hypercard as a teaching tool". En RAHTZ, S. P. (Ed.): Computers and Quantitative Methods in Archaeology, Proccedings of the 1989 CAA Conference (Birmingham, 1989). BAR International Series. Núm. 565. Oxford.

RHEINGOLD, H. (1991): Virtual reality. London. Secker and Warburg.

RICHARDS, J. D. (1985): Data processing in Archaeology. Cambridge. University Press.

ROSA, D.-MOREIRA, J. M. (1987): Evaluación Ecológica de los recursos Andalucía. Sevilla. AMA.

RYAN, N. S. (1988): "Bibliography of computer applications and quantitative methods". En RAHTZ, S. P. (Ed.): Computers and Quantitative Methods in Archaeology. Proccedings of the 1988 CAA Conference (Birmingham, 1988). BAR International Series. Nún. 446. Oxford.

RUIZ, G. (1991): “Arqueología y Universidad. La Reproducción del Sistema”. Revista de Arqueología. Núm. 118. Madrid. 1991.

SANCHEZ, J. (1985): "ANEXOS IV: Un "experto" en economía de la Edad del bronce". Cuadernos de Prehistoria y Arqueología. Núm. 11-12. Madrid.

SANCHEZ, J. (1986): "La importancia de la Informática en los estudios de Aueología". I Jornadas de Metodología Arqueológica de Murcia. Manuscrito Multicopiado. Murcia. 
SHENNAN, S. J. (1987): "Trends in the study of late european Prehistory" Annual Review of Anthropology. Núm. 6.

SHENNAN, S. J. (1989): Quantifying Archaeology. Edinburgh. University Press.

SHENNAN, S. J. (1989): "Archaeology as Archaeology an the Binford's New perspectives in Archaeology twenty years on" Antiquity. Núm. 63.

SOARES, A. M. (1984): Carta Ecológica. Noticia explicativa do Atlas do Ambiente de Portugal. Lisboa. Comissao Nacional do Ambiente.

SHRODT, P. A. (1984): El microordenador en las Ciencias Sociales.Barcelona. Crítica.

TEDA, (1988): "Registro informático y Arqueologá en Tarragona". En LIBERTI, A. M. (Ed.): Archeología e Informática. Roma. Casa Editrice Quasar. 1988.

UNIMAP (1989): User's manual. Soborg. UNIRAS.

VILA, A.-ESTEVEZ, J. (1989): "Sola ante el peligro: la Arqueología ante las ciencias auxiliares" Archivo Español de Arqueología. Núm. 62. Madrid. CSIC.

WAGSTAFF, J. M. (1987): “The New Archaeology and Geography”. En WAGSTAFF, J. M. (Ed.): Landscape and Culture. Oxford. Blackwell.

WANSLEEBEN, M. (1988): "Geographic Information Systems in archaeological research". En RAHTZ, S. P. (Ed.): Computers and Quantitative Methods in Archaeology. Proceedings of the 1988 CAA Conference (Birmingham, 1988). BAR International Series. Núm 446. Oxford.

WATSON, D. (1989): WINSOM: User's guide and reference manual. Winchester, IBM-UK Scientific Center.

WHEATLY, D. (1991): "SYGRAF resource based teaching with graphics". En LOCKYERAR, K.-RAHTZ, S. P. (Eds.): Computer applications and quantitative methods in Archaeology. Proceedings of the 1990 CAA Conference (Oxford, 1990). BAR International Series. Núm. 565. Oxford.

WRIGHT, R. (1989): Doing Multivariate Archaeology and Prehistory. Handling large datasets with MV-ARCH. Sidney. Department of Anthropology.

ZUBROW, E. B. W. (1990): "The fanfasies of GIS software". En ALLEN, K. et alli (Eds.): Interpreting Space. GIS and Archaeology. London. Taylor and Francis. 